\title{
LA HERMENÉUTICA TEMPRANA DE HEIDEGGER
}

\author{
CARLOS B. GUTIÉRREZ \\ DEPARTAMENTO DE FILOSOFIA \\ UNIVERSIDAD NACIONAL DE COLOMBIA
}

Quienes estudiamos con Gadamer supimos siempre de su cálida admiración por las lecciones del joven Heidegger en la primera mitad de los años veinte, primero en Friburgo y luego en Marburgo, de las cuales salieron los impulsos decisivos para lo que hoy conocemos como filosofía hermenéutica. Mucha curiosidad nos inspiraba el hecho de que al aparecer Ser y tiempo en 1927, asistentes a esas lecciones tempranas se refirieron al nuevo libro en términos que sugerían que éste estuviera muy por debajo del nivel de originalidad filosófica alcanzado en ellas, coincidiendo aparentemente con la afirmación del autor, por razones bien diferentes, de que Ser y tiempo hubiese sido "un accidente fatal". ${ }^{1}$ Y la nota al final del $\S 15$ de Ser y tiempo, en la que Heidegger advierte al lector que "desde el semestre de invierno 1919-1920 expuso repetidamente en sus cursos" la "hermenéutica de la facticidad" del "ser ahí" en general, ${ }^{2}$ atizaba nuestra curiosidad por el incógnito portento; pues si bien mucho de la Hermenéutica inicial quedó incorporado al libro, ello sucedió, en opinión de muchos, al servicio de preguntas que llegaron hasta hacer irreconocible el horizonte hermenéutico fundamental. Para no hablar de la obra tardía de Heidegger en la que, si se exceptúa el diálogo acerca del habla (escrito a propósito de la visita del profesor japonés Tezuka entre 1953 y 1954), prácticamente desaparecen las referencias a la Hermenéutica - hasta llegar al claro deslindamiento según la afirmación de 1973 de que "la filosofía hermenéutica es el asunto de Gadamer, que constituye un buen contrapeso a la filosofía analítica y a la Lingüística". ${ }^{3}$

1 Max Kommerell, Briefe und Aufzeichnungen 1919-1944, von I. Jens (ed.), Olten/Friburgo de Brisgovia, 1967, p. 405.

2 Martin Heidegger, El ser y el tiempo, Fondo de Cultura Económica, México 1962, p. 85.

3 Otto Pöggeler, Heidegger und die hermeneutische Philosophie, Friburgo/Munich, 1983, p. 395 . 
La situación ahora es muy distinta toda vez que las más importantes de aquellas lecciones como son las que se ocupan de las Interpretaciones fenomenológicas de Aristóteles (1921) ${ }^{4}$ y de Ontología (Hermenéutica de la facticidad) $(1923)^{5}$ ya han salido a luz, lo mismo que el importante manuscrito Indicación de la situación hermenéutica, ${ }^{6}$ introducción a las interpretaciones de Aristóteles que Heidegger escribió en el otoño de 1922 por solicitud de Paul Natorp para efectos de su nombramiento como catedrático en Marburgo. Las nuevas fuentes evidencian los trazos y los motivos de la hermenéutica anterior a Ser y tiempo de la cual nos vamos a ocupar en este trabajo a fin de mostrar los impulsos decisivos que de ella resultan para la articulación de lo que hoy se conoce como filosofía hermenéutica, años antes de la radicalización de la temporalidad de la existencia humana en la analítica ontológica del "ser ahr".

\section{Un Aristóteles novedoso}

Heidegger, fuertemente impresionado aún por la fenomenología de Husserl, descubre a un Aristóteles bien distinto del que conoció como joven estudiante de teología y lo hace ahora en medio de la agitación de la República de Weimar desde el horizonte de las más candentes cuestiones de la filosofía en torno al concepto de vida, del que se valían por aquella época, con razón o sin ella, las muchas variantes de la "filosofía de la vida" —ese grito de protesta contra el progresismo liberal y la racionalidad técnica e industrial que se hizo sentir de un extremo a otro de Europa a raíz de la Segunda Guerra Mundial. El problema de la auto-interpretación de la vida del que se habia ocupado leyendo a Dilthey le sirve a Heidegger de inspiración para bosquejar a partir de Aristóteles y ahora influenciado por Kierkegaard los lineamientos de una antropología filosófica y fenomenológica. ${ }^{7}$ La motivación, sin embargo, seguía siendo ante todo teológica: en búsqueda de una interpretación adecuada y de una comprensión antropológica de la conciencia cristiana en contra de la neoescolástica y de la teología católica de entonces, Heidegger cree que habría que volver a Aristóteles para comprender realmente la historia cristiana de occidente y para hacer transparente la

4 Martin Heidegger, Phänomenologische Interpretationen zu Aristoteles. Einführung in die phänomenologische Forschung, Gesamtausgabe t. 61, Francfort del Meno, 1985.

5 Martin Heidegger, Ontologie (Hermeneutik der Faktizität), Gesamtausgabe t. 63, Francfort del Meno, 1988.

6 Martin Heidegger, Phänomenologische Interpretationen zu Aristoteles (Anzeige der hermeneutischen Situation), en Dilthey-Jahrbuch für Philosophie und Geschichte der Geisteswissenschaften, t. 6, Gotinga, 1989.

7 Véase, Hans-Georg Gadamer, "Heideggers 'theologische' Jugendscrift", en Dilthey-Jahrbuch, op. cit., p. 230. 
situación histórica que se vive. Se trataba pues de hacer hablar de nuevo, a partir de la comprensión vital del momento, a la Antropología de Aristóteles, ganada a su vez a partir de la vida vivida fácticamemte tal como se echa de ver en la Retórica y en la Ética. Podría decirse que el joven Heidegger buscaba entonces desplegar sus interrogantes radicales a partir de la experiencia de su propia vida y en el reconocimiento de las experiencias de la propia vida en las experiencias de los griegos.

Heidegger, quien había dado ya varios seminarios sobre la Ética a Nicómaco, sabía de la importancia de la "phronesis" como aclaramiento práctico de la propia vida, como prudencia que se manifiesta en el actuar mismo. Ahora, no obstante, le interesa la relevancia de la filosofía práctica para la ontología, por dos motivos encontrados que lo llevan a movilizar a Aristóteles contra Aristóteles mismo, en lo que ya da en llamar "destrucción de Aristóteles": 8 de un lado, el distanciamiento crítico frente al concepto de ser y de lo divino como lo ente que se mantiene en el presente de una constante plenificación que no deja absolutamente nada por fuera de sí; y por el otro, el llamado a lo propio del ser del ser humano, que trata de encontrar en la facticidad del existir y en su aclaramiento en Aristóteles. Éste, como es sabido, le reconocía a la "sophia" un rango superior al de la "phronesis" ya que en la primera se da en su plenitud el percibir de lo constante que en la segunda sólo se da de manera imperfecta; Heidegger, guiándose por la forma originaria del saber de la vida, retrorrefiere la forma desarrollada de la filosofía teórica a la forma originaria de la filosofía práctica: puesto que en la "phronesis" se percibe directa e inmediatamente la presencia de aquello en razón de lo cual se hacen consideraciones y se toman decisiones, en la "phronesis" hay "nous"; la filosofía práctica resulta así ser la verdadera filosofía teórica. Podríamos decir que Heidegger se empeña en reeemplazar el sentido teórico por el sentido "fronético" de la filosofía, buscando al mismo tiempo la ontologización de los rasgos fundamentales de la vida.

De ahí que el centro de gravedad del pensamiento aristotélico se desplace para Heidegger a la Física, que se ocupa de la cualidad de ser movido y no de la idealidad del orden matemático de sesgo pitagórico o platónico. Esa cualidad no es movimiento; a ella no se opone por tanto la quietud. La cualidad de ser movido es el íntimo entretejimiento de quietud y movimiento en que consiste ser; para ella Aristćteles acuñó el término "energeia" que designa a un ser activo que no se encamina primeramente al logro de objetivos sino que está siempre en camino, en obra. "El ser movido de la vida fáctica es precedentemente interpretable y descriptible como la intranquilidad." ${ }^{\prime} \mathrm{El}$ investigar filosófico mismo es visto ahora como "la explícita consumación

8 Klaus Figal, Heidegger zur Einführung, Junius Verlag, Hamburgo, 1992, pp. 56-64.

9 Martin Heidegger, Phänomenologische Interpretationen zu Aristoteles, op. cit., p. 93. 
del ser movido fundamental de la vida fáctica que siempre se mantiene dentro de él". ${ }^{10}$ Las que Heidegger llama "categorías del sentido relacional de la vida", a saber: inclinación, distancia y cerramiento contienen ya en la expresión, según él, "la indicación de movimiento". ${ }^{11}$ En el conjunto mocional de "relucencia" - alumbramiento de sí y del entorno del curary "preestrucción" —cuidar anticipante- se da el ser movido de la vida que resulta en un automovimiento propio en cuanto que la vida vive hacia afuera a partir de sí. ${ }^{12} \mathrm{El}$ arruinamiento (caída) se define como "el ser movido de la vida fáctica que consuma en ella misma como ella misma para ella misma a partir de sí y en todo ello contra sí misma". ${ }^{13}$ A Heidegger le interesa en especial la ambivalencia o contratensionalidad indisoluble que distingue al movimiento de la vida como tal: en la lección de 1921, bajo el rubro de "Categorías fundamentales de la vida", se encuentran inseparablemente entrelazadas de un lado la "inclinación" (sentido relacional de la vida con el mundo) y del otro el "arruinamiento", la tendencia cadente que resulta de la indigencia, de las carencias de la vida fáctica (Darbung). ${ }^{14}$ A esto justamente alude también la célebre afirmación de que "la vida es brumosa, se enniebla siempre de nuevo a sí misma". ${ }^{15}$

A la pregunta acerca de la importancia real de su planteamiento, es decir, al interrogante de por qué necesite la vida de hermenéutica, Heidegger responde en términos de razón práctica. La vida necesita de interpretación porque lo que cuenta en la vida es un ser despierto que la mayoría de las veces se marra o se encubre, un ser despierto o alerta que sólo puede volverse consciente a través del ejercicio hermenéutico. Del tratado Peri hermeneías de Aristóteles dice Heidegger que "trata del 'lógos' en su logro fundamental de des-encubrir lo que es y de familiarizarnos con ello" y unas líneas más adelante hace énfasis en que "el 'lógos' tiene la destacada posibilidad de obrar 'aletheúein' (hacer disponible lo previamente oculto y encubierto como desoculto y abierto)". ${ }^{16}$ La hermenéutica, en otras palabras, procede contra el auto-encubrimiento de la facticidad. La movilidad inclinante de la vida tiene un aspecto cadente o arruinante, toda vez que el ser humano en vez de asumir y tomar en sus manos la propia existencia cae en la interpretación pública de su ser. De ahí que la hermenéutica tenga por tarea

10 Martin Heidegger, Anzeige der hermeneutischen Situation, op. cit., p. 239.

11 Martin Heidegger, Phänomenologische Interpretationen zu Aristoteles, op. cit., p. 100.

12 Ibid., p. 130.

13 Ibid., p. 131.

14 Ibid., p. 155.

15 Hans-Georg Gadamer, "Erinnerung an Heideggers Anfänge", en Gesammelte Werke, t. 10, Tubinga, 1995, p. 11.

16 Martin Heidegger, Ontologie (Hermeneutik der Faktizität), op. cit., pp. 10-11. 
la de seguirle la pista a la enajenación ${ }^{17}$ y hacerla consciente, ya que en tanto el ser humano se abandone acríticamente a determinaciones que le son ajenas se excluye a sí mismo del lúcido poder ser que él es como ser ahí. La hermenéutica de la facticidad se esfuerza por abrir al ser ahí como un ente que no es como tal "objeto de indiferente opinar teórico". ${ }^{18} \mathrm{Y}$ puesto que con la objetividad indiferente se erige como principio a la acriticidad, la hermenéutica se entiende a sí misma como crítica de la acriticidad de la concepción tradicional del ser humano. El joven Heidegger, como vemos, cree que a raíz del aclaramiento buscado la existencia humana puede llegar a volverse transparente a sí misma y permitir con ello, a pesar de su condicionalidad, la escogencia de una posibilidad propia. La obra tardía, por el contrario, mostrará que una opacidad última constituye la esencia verdadera de la historia y de la destinación humana.

Con Heidegger en 1922 no es la teoría de la interpretación sino el interpretar mismo el quehacer de una hermenéutica elevada a filosofía con miras a alcanzar la auto-transparencia del ser del ser humano, sabiendo que el trabajo filosófico de esclarecimiento tan sólo lleva cabalmente hasta su fin la interpetación inherente a la movilidad del existir. La interpretación de la situación hermenéutica propia es la instancia que le permite al ser humano contrarrestar su tendencia cadente, destruyendo críticamente la concepción del ser humano como objeto de teorias indiferentes, supuestamente neutras, y desplegando en su lugar el poder ser que hay que asumir expresamente. Frente a la auto-conciencia enajenada del ser humano se evidencia la necesidad de una hermenéutica de la facticidad que vuelva a recordar a la existencia de sí misma. Muchos ven aquí, siguiendo a Riedel, ${ }^{19}$ el inicio de la rehabilitación de la filosofía práctica en el siglo xx que habrán de adelantar discípulos del Heidegger temprano entre quienes se cuentan Gadamer, Leo Strauss, Hannah Arendt y Hans Jonas. Como quiera que sea, la hermenéutica inicial de Heidegger habla a trechos con el tono de una crítica ideológica de sesgo "jovenhegeliano" que en nombre de un ser despierto por conquistar se rebela contra la auto-enajenación actual del ser humano. ${ }^{20}$ No está de más anotar que en aquel mismo año (1923) Georg Lukács propone también su crítica a la enajenación bajo el título de Historia y conciencia de clase. En el fondo, sin embargo, la "hermenéutica

17 Ibid., p. 15.

18 Ibid., p. 3.

19 Manfred Riedel, "Der hermeneutische Weg zur 'Rehabilitierung der praktischen Philosophie'", en Politik, Philosophie, Praxis. Festschrift für Wilhelm Hennis zum 65. Geburtstag, Stuttgart, 1988, p. 283.

20 Jean Grondin, "Das junghegelianische und ethische Motiv in Heideggers Hermeneutik der Faktizität", en Der Sinn für Hermeneutik, Darmstadt, 1994. 
de la facticidad" critica al malentendido de sí mismo, al no dar en sí mismo del ser ahí o "arruinamiento" que en Ser y tiempo se va a llamar "caída".

$\mathrm{El}$ análisis de Heidegger mantiene eso sí un carácter indicativo-formal. No se trata para él ni de precisar las formas sociales de auto-enajenación ni de ofrecer un catálogo de soluciones. Ni muchísimo menos de filosofemas que otros tengan que repetir. Los conceptos de que se vale ofrecen tan sólo orientación formal hacia una situación de decisión, cuya forma concreta queda siempre en manos del ser ahí respectivo; el ser despierto, de alcanzarse, debe acaecer como logro propio. El sentido primario de los enunciados sobre el ser del existir humano no es el de describir teóricamente algo dado como objeto sino el de "permitir comprender ser ahi" que suscite la realización interpretativa específica del ser ahí. Enunciados filosóficos semejantes tienen, pues, el carácter de indicaciones que uno sólo comprende en la medida en la que uno mismo, a su manera y bajo responsabilidad propia, trate de reạlizarlas. Estamos en el ámbito de la "indicación hermenéutica" ${ }^{21}$ que se articula en conceptos "accesibles únicamente en la constante renovación interpretativa". ${ }^{22}$ Hermenéutico es aquí el enunciado que llama a la auto-aplicación, con lo cual estamos de nuevo en la cercanía de Aristóteles. La indicación es "vacía" en cuanto carece de objeto, pero "decisiva" y determinante en cuanto a orientación. ${ }^{23}$

Aquí vuelven a plantearse serias dudas en cuanto al estatuto filosófico de la hermenéutica. "No hay un 'universal' del comprender hermenéutico que rebase lo formal", ${ }^{24}$ insiste en la lección de 1923. La hermenéutica que surge de la movilidad del ser ahí no puede en su formalidad sustituir al respectivo existir. No debe entonces sorprender que Heidegger opte por situar a la hermenéutica por fuera de la filosofía: "Yo supongo, si se permite esta acotación personal, que la hermenéutica no es en absoluto filosofía sino algo bien provisional, que no obstante tiene su más alta peculiaridad: no se trata de terminar con ella tan rápido como sea posible, sino de permanecer en ella tanto como se pueda." Y añade: "La hermenéutica misma no es filosofía: ella se limita a ofrecer al filósofo de hoy un objeto hasta ahora caído en el olvido para que le preste decidida atención." 25 La hermenéutica parece valer como auto-crítica de la filosofía y tener por tanto que asumir la forma de destrucción de la filosofía precedente. El objetivo de una hermenéutica

21 Martin Heidegger, Logik. Die Frage nach der Wahrheit, Gesamtausgabe t. 21, Francfort del Meno, 1976, p. 410.

22 Martin Heidegger, “Anmerkungen zu Karl Jaspers' Psychologie der Weltanschauungen" (1919/1921), en Wegmarken, 2. Auflage, Klostermann, Francfort del Meno, 1978, p. 9.

23 Martin Heidegger, Phänomenologische Interpretationen zu Aristoteles. op. cit., p. 33.

24 Martin Heidegger, Ontologie (Hermeneutik der Faktizität), op. cit., p. 18.

25 Ibid., p. 20. 
critica de la facticidad, que llama al ser ahí de retorno a sí mismo y a su posible libertad, es el de desmontar las definiciones del ser humano legadas por la tradición y como tales incuestionadas; para ello Heidegger se vale ya de su formidable talento para desentrañar tanto la multiposicionalidad de las palabras como la fucrza interna de gravedad del uso vivo de ellas y de sus implicaciones semánticas. "iHermenéutica es destrucción!"26 afirma Heidegger categóricamente en el primero de los manuscritos complementarios de la lección. Y esta destrucción se dirige, por lo pronto, contra la ahistoricidad de la Fenomenología, que había sido puesta en evidencia por el reto del historismo. La historicidad de la existencia humana se muestra en que ésta es siempre la del caso, y a esta existencia del caso cada vez se le plantea ininterrumpidamente la tarea de aclararse a sí misma en su facticidad. El atisbo medular de la hermenéutica de la facticidad, por curioso y paradójico que parezca, es el de que en el factum de la existencia haya comprender y de que el ser ahí mismo sea hermenéutico. Originalmente "factum" y "facticidad" fueron conceptos contrapuestos a todas las verdades de razón y designaban, tal como el factum racional de la libertad, todo lo que uno no puede explicar y tiene por tanto que limitarse a aceptar, es decir, el límite insuperable de toda constatabilidad histórica y de toda objetivabilidad. ¿Qué es entonces, podemos preguntar, la "fenomenología hermenéutica" de la que tanto se habla en las lecciones? La Fenomenología deja ya de ser reflexión, es decir, intencionalidad de orden superior, para convertirse en comprender proyectante-interpretador. ${ }^{27}$ El curar de, el andar en algo, pasa a ser el sentido cabal y originario de intencionalidad. ${ }^{28}$ El fundamento de todo sentido no es ya la subjetividad transcendental que constituye su mundo a través de actos intencionales sino la facticidad de un ahí, de una apertura en comprensión actuante de lo que es.

La expresión "hermenéutica de la facticidad" resulta pues altamente paradójica. "Facticidad", dentro del contexto neokantiano en el que se movió el joven Heidegger, era el término opuesto a "logicidad": en tanto que lo lógico concernía a lo universal transtemporal, lo fáctico aludía a lo temporal, a lo contingente, individual e irrepetible. En un contexto más amplio, sin embargo, "facticidad" era el concepto contrapuesto a todo lo que fue conciencia, autoconciencia o espíritu en el idealismo alemán o ego transcendental en Husserl. Hermenéutica de la facticidad no puede significar algo así como un interpretar que pretenda comprender a la facticidad como tal, pues sería un contrasentido querer comprender lo que no es más que fáctico y como tal.

26 Ibid., p. 105.

27 Véase, Friedrich-Wilhelm von Hermann, Hermeneutische Phänomenologie des Daseins, t. I, Francfort del Meno, 1987.

28 Martin Heidegger, Phänomenologische Interpretationen zu Aristoteles, op. cit., p. 98. 
cerrado a todo sentido. Hermenéutica de la facticidad quiere decir más bien pensar la existencia misma como realización o consumación de comprensión e interpretación. La reflexión filosófica sería entonces la explicitación del fundamental ser ya siempre interpretado de la vida.

\section{La precomprensión}

Ocupémonos ahora de los principales atisbos en torno al fenómeno del comprender a lo largo de las lecciones tempranas de Friburgo y Marburgo hasta desembocar en Ser y tiempo. El comprender humano se guía siempre por la precomprensión que surge de la respectiva situación existencial, precomprensión que determina el marco y la amplitud de validez de todo intento interpretativo explícito. Esta estructura previa del comprender o "comprender primario" significa que el ser del ser humano se caracteriza por un ser ya interpretado que le es propio y que precede a toda enunciación, ser cuyo carácter fundamental corre permanente peligro de quedar encubierto por la tendencia niveladora del juicio proposicional. Así pues la "hermenéutica de la facticidad" quiere ser la hermenéutica de todo lo que obra detrás del enunciado o previamente a él y, como tal, una interpretación del curar fundamental de la existencia humana que se pronuncia antes y por detrás de todo juzgar proposicional. El comprender como la forma más elemental de realización del ser del hombre se ve así despojado de su carácter puramente epistémico, en abierto contraste con la hermenéutica decimonónica que en un principio tuvo al comprender por un inteligir teórico en el que se trataba de aprehender intelectualmente algo con sentido. Con Droysen, Dilthey y los neokantianos del suroeste alemán el comprender llegó a ser tenido por un proceso autónomo de conocimiento llamado a fundamentar la índole metodológica específica de las ciencias del espíritu. Para Heidegger comprender deja finalmente de ser el concepto metodológico de una operación que a contrapelo de la vida tiende hacia la idealidad del sentido y deviene rasgo ontológico fundamental de la vida humana misma.

Valga anotar que el interés de Heidegger en el tema de la precomprensión se nutre en parte de atisbos ganados en indagaciones en torno a la noción de "ousía" en el libro VII de la Metafísica de Aristóteles, noción que como es sabido guarda relación semántica con el patrimonio del labrador, con aquello de lo que está a su disposición en su trabajo y en su granja, es decir, con lo tenido y lo propio como pertenencia. En el curso de 1921 sobre $D e$ anima, anota Heidegger que para que ser sea intuitivamente dado tiene primero que ser tenido. ${ }^{29} \mathrm{El}$ principio fenomenológico del darse algo en

29 Theodore Kisiel, The Genesis of Heidegger's Being \& Time, University of California Press, 1995, p. 233. 
completud perceptiva es puesto en tela de juicio a la luz del sentido precientífico de tener: es a partir de las experiencias previas del tener que surge toda cuestión científica o filosófica. El cómo del preguntar ya está determinado por el sentido del que antes de ser consciente es un "tener vivido". Justamente la formación de los conceptos aristotélicos muestra aún una estrecha cercanía a la actitud natural de familiaridad pre-científica, una ingenuidad teórica en sentido eminente y positivo.

La lección del semestre siguiente, en el invierno de 1921, se ocupa del carácter intrínsecamente histórico de la indagación ontológica de acuerdo con la movilidad histórica de la vida misma. "Filosofía es conocimiento histórico (es decir, histórico-consumantemente comprensivo) de la vida fáctica." ${ }^{30} \mathrm{~A}$ propósito de la definición de filosofía, Heidegger recuerda más adelante que definir es un determinar "quod tenendum et credendum declaratur, manifestatur et indicatur" ${ }^{31}$ y articula por primera vez una noción cabal del contexto presuposicional de la interpretación con el nombre de "situación hermenéutica", ${ }^{32}$ llamada pocas páginas atrás "situación del comprender", como introducción a los textos aristotélicos. Un año más tarde la introducción al proyectado libro sobre Aristóteles llevará por título Indicación de la situación hermenéutica.

La concepción heideggeriana del comprender primario se remite a la expresión alemana "sich auf etwas verstehen", entenderse en o hacia algo, entender de algo, ser capaz de algo, expresión que gracias a su forma reflexiva tiene una valencia más ontológica que cognitiva y apunta por tanto menos a un disponer de información teórica que a una determinada habilidad o capacidad. Entender de algo equivale a estar a la altura de algo, a estar en condiciones de arreglárselas con algo, aludiendo con ello generalmente a una capacidad no ostentativa ni sofisticada más bien a manera de un arte. Toda nuestra vida se entreteje con semejantes habilidades; es así como decimos que alguien entiende del trato con la gente, de política, de futbol, de construcción, de baile, de la buena mesa, de mujeres -o de hombres, según sea el caso- iy hasta de filosofía!, sin que la persona en cuestión disponga de una articulación teórica especial de ello. No olvidemos que comprender teóricamente algo significa también al fin y al cabo estar a la altura de ese algo, arreglárselas con ello. El saber práctico de que hablamos es para Heidegger un "existencial", un modo de ser fundamental del ser humano. El comprender visto así es menos una manera de conocer que un orientarnos en el mundo en el diario curar de, en el andar en algo en que consiste fundamentalmente nuestra existencia.

30 Martin Heidegger, Phänomenologische Interpretationen zu Aristoteles, op. cit., p. 2.

31 Ibid., p. 17.

32 Ibid., p. 38. 
La comprensión actuante en que consiste nuestra orientación fundamental no es explícita de ordinario. Como manera de ser del ser humano no es para sí temática; vivimos demasiado en ella y de ella como para que necesite ser notoria o señalada. $Y$, sin embargo, todo aquello con lo que tenemos que ver en el mundo de la vida está siempre ya pre-interpretado como algo para esto o para aquello dentro de ese precomprender orientador. Fue así que el término griego para cosa, "pragma", emergió del contexto de la "praxis", del tener que ver en lo que andamos con las cosas. El "como" o "en tanto que" práctico nombra rasgos de comprensión que se dan siempre de una manera no llamativa en el tener que ver el ser ahí con su mundo. Heidegger pone de relieve esta no notoriedad al diferenciar el "como" hermenéutico del "como" apofántico. ${ }^{33}$ Más originalmente que el "como" apofántico, es decir, que el ser interpretado de los fenómenos que se articula en la predicación expresa de enunciados declarativos, actúa el "como" hermenéutico que resulta del precomprender interpretativo fundamental de la existencia humana. Esta tesis, que contradice buena parte de la filosofía contemporánea del lenguaje, se corrobora a cada paso. Así, por ejemplo, cuando entramos a un recinto o a un vehículo comprendemos para qué sirve una puerta sin perder palabra alguna sobre tamaña trivialidad. "La estructura del como no está al mismo tiempo necesariamente ligada a la predicación. En el tener que ver con algo no hago enunciados temáticos predicativos sobre ello." 34 La estructura del "como" es esencialmente ante-predicativa pues forma simplemente parte de nuestro comportamiento: "Yo soy qua ser ahí trato comprensivo." 35 Es muy diciente que Heidegger llame "hermenéutico" justamente al comprender ante-predicativo, haciéndose eco del empeño de la Hermenéutica a partir de Schleiermacher en alcanzar lo que está antes del enunciado, radicalizándole eso sí al fundamentar la universalidad de ese comprender en el curar de como rasgo ontológico del ser humano.

La insistencia en la dimensión ante-predicativa del "comprender primario" no significa que se desconozca el lenguaje. Se trata de precavernos, eso sí, ante la desfiguración de la relación hermenéutica primaria con el mundo que resulta de la tendencia objetivizante y como tal, niveladora de los enunciados proposicionales. Lo que quiere Heidegger es que en el lenguaje oigamos al curar de que habla allí también y atendamos al "como" de la precomprensión actuante que hace posible la estructura del lenguje predicativo. ${ }^{36}$ Recordemos el trillado ejemplo del martillo a propósito del

33 Ibid., p. 177.

34 Martin Heidegger, Logik. Die Frage nach der Wahrheit, en Gesamtausgabe t. 21, Francfort del Meno, 1976, p. 144.

35 Ibid., p. 146.

36 Ibid., p. 145. 
ser a la mano de los útiles, cuyo rasgo esencial es el de retraerse, de no llamar la atención sobre sí, de manera que el operario pueda adelantar su labor sin tener que ocuparse temática y observacionalmente de la herramienta. ${ }^{37}$ Al martillar, sin embargo, el obrero muchas veces se cansa y al sentir de manera cada vez más gravosa la pesantez comprende al martillo prácticamente "como" pesado, interpretación que normalmente se lleva a cabo poniendo a un lado el martillo, descansando, maldiciendo o cambiando de herramienta y no articulando explícitamente un enunciado proposicional sobre un objeto observacional al que ahora se atribuye una propiedad. El enunciado cosifica pues la relación hermenéutica original de manera que el "con" del tener que ver actuante se transforma en el "sobre que" de un distanciado señalar observacional. La cosificación es tan radical que al final los enunciados tienden a ser tenidos por meras opiniones subjetivas sobre hechos dados con objetividad total, tendencia que nos lleva a desconocer el arraigo del lenguaje en la estructura del curar de y a volvernos sordos a lo que en el habla inmediatamente no se dice y, sin embargo, es parte de lo que se quiere decir.

Detrás del ocuparnos dispositivamente de las cosas del mundo está en precedencia ontológica el curar fundamental, el curar de sí mismo del ser ahí. Éste, el ser ahí, se caracteriza porque en su ser a él le va su ser, su poder ser en el mundo. El comprender como modo de ser viendo en torno tiene sus raíces en el curar de sí mismo del ser ahí, a partir del cual se determina el carácter específico de proyecto de nuestro comprender. Para adelantarse al mundo se guía nuestro comprender por ciertos proyectos tácitos que encarnan nuestras posibilidades, nuestro poder ser. Comprender es así realizar una determinada proyección y no otras. Originalmente no están dadas las cosas en objetiva pureza para que adquieran luego cierta coloración a través de nuestra comprensión "subjetiva". iNo! "El simple tomar, tener algo, en el tener que ver a la manera del 'como algo' es tan originario que un concebir que habría que llamar libre del 'como', del 'en tanto que', requiere primero de una redisposición transformadora, asumiendo que sea ella en principio posible." 38 Lo que hay originalmente es nuestro tener que ver con el mundo en la forma de proyectos comprensivos. La visión puramente teórica del mundo, cuya posibilidad jamás cuestiona Heidegger, se basa en una suspensión expresa de esos proyectos del curar fundamental. Primaria es la dimensión del "como" hermenéutico en la que todo lo que es encuentra y nos afecta.

Claro está que nuestros proyectos no están a nuestra disposición; somos más bien nosotros los que estamos arrojados, insertos en ellos. Forma parte

37 Martin Heidegger, Ser y tiempo, op. cit., $\$ 15$.

38 Martin Heidegger, Logik. Die Frage nach der Wahrheit, op. cit., p. 145. 
de la pre-estructura fáctica del comprender el que éste se encuentre dentro de perspectivas previamente dadas que orientan sus expectativas de sentido. "Estos respectos tácitamente disponibles la mayoría de las veces, en los que cae la vida fáctica más por vía de costumbre que por apropiación expresa, le pre-determinan a la movilidad del curar los caminos de su realización."39 $\mathrm{Y}$, sin embargo, no estamos ciegamente abandonados en manos de la preestructura de lo ya interpretado como si estuviésemos presos sin remedio de nuestros prejuicios, tal como lo sugieren los críticos iluminados del círculo hermenéutico. Muy por el contrario, la hermenéutica de Heidegger busca el esclarecimiento explícito de esa pre-estructura, esclarecimiento que ahora se llama "interpretación".

\section{Interpretar como explicitación de lo precomprendido}

Tradicionalmente fue la interpretación el medio para llegar a la comprensión como intelección; por eso quien no comprendía un texto acudía a una interpretación, cuya finalidad natural era el logro de comprensión. Primero venía pues la interpretación y luego, a partir de ella, el comprender. En una nueva contestación de la tradición Heidegger invierte el orden de los elementos: primario es ahora el comprender, la interpretación es tan sólo su desarrollo o elaboración.

La nueva noción de interpretación es, sin embargo, crítica. ${ }^{40}$ El comprender que vive siempre de un determinado y para su situación específico ser ya.interpretado, tiene la posibilidad de desarrollarse como tal, de comprenderse a sí mismo. Tal es el auto-esclarecimiento que aporta la interpretación cabal como análisis de lo ya implícitamente comprendido. En la interpretación, dice Heidegger en el $\S 32$ de Ser y tiempo, "el comprender se apropia comprendiendo lo comprendido. En la interpretación el comprender no se vuelve otra cosa, sino él mismo". ${ }^{41}$ En realidad la interpretación ayuda a que el precomprender se haga transparente a sí mismo; ella sirve ante todo para apropiar la situación de la comprensión y los presupuestos que determinan el conocer y el comportarse del curar del ser ahí; su empeño crítico busca evitar hasta donde sea posible el malentendido propio, el malentendido de sí mismo. Puesto que nuestro comprender puede equivocarse, todo esfuerzo de comprensión requiere entonces de "apropiación, de consolidación y de salvaguardia"; ${ }^{42}$ de ahí que la primerísima tarea de toda honesta interpre-

39 Martin Heidegger, Phänomenologische Interpretationen zu Aristoteles (Anzeige der hermeneutischen Situation, en Dilthey-Jarbuch, 6/1989, p. 241.

40 Jean Grondin, Einführung in die philosophische Hermeneutik, Darmstadt, 1991, pp. 125 ss.

41 Martin Heidegger, Ser y tiempo, op. cit., p. 166.

42 Martin Heidegger, Prolegomena zur Geschichte des Zeitsbegriffs, Gesamtausgabe t. 20, Francfort del Meno, 1979, p. 358. 
tación deba ser la de hacer consciente en reflexión la propia pre-estructura del comprender. No en vano insiste Heidegger en la segunda sección de Ser y tiempo en la necesidad de aclarar la situación hermenéutica de la analítica del ser ahí para poder pasar a una exégesis original del ser del hombre al hilo de la temporalidad. ${ }^{43}$

Esto no quiere decir que, para dar un ejemplo, la interpretación de un texto se agote en desplegar la precomprensión del intérprete sin consideración alguna del texto a interpretar y sí, más bien, que para interpretar adecuadamente un texto haya primero que hacer transparente la situación hermenéutica propia para que así lo ajeno o lo otro del texto pueda hacerse valer por sí mismo, es decir, sin que los pre-juicios inconscientes del intéprete ejerzan su imperceptible dominio y encubran la alteridad del texto. Para comprender hay que hacer consciente lo previamente juzgado y así arriesgarlo y ponerlo en juego frente a la alteridad de lo diferente; si no lo hacemos quedaremos condenados a la prisión de lo propio. Así como se dice que quien ignora la historia termina repitiéndola, cabe aquí decir que quien ignora su situación hermenéutica corre el riesgo de abandonarse acríticamente a ella. Heidegger alude a esto en la Indicación de la situación hermenéutica a propósito de la confrontación de la filosofía con su historia: "Todas las interpretaciones en el campo de la historia de la filosofía e igualmente en otros, que en contraposición a 'construcciones' de las que se dan en las historias de problemas se ufanen de no proyectar lo propio en los textos, tendrán que dejarse sorprender en flagrante cometer lo que repudian sólo que sin orientación y con medios conceptuales de la más variada e incontrolada proveniencia." 44 Por tanto sólo mediante el volver reflexivo a la pre-estructura propia será posible controlar en cierta manera el ser ya interpretado de transfondo a fin de que la alteridad de aquello que se trata de comprender pueda salir a relucir frente a él.

Es a partir de este empeño crítico en la auto-comprensión como se puede explicar en la filosofía de Heidegger la acogida del círculo hermenéutico por cuya superación tanto se afanó el historismo. Desde luego que hay circularidad entre interpretar y comprender, sólo que esta circularidad es parte de la estructura ontológica del ser ahí. Lo que cuenta no es cerrar los ojos ante el supuesto círculo vicioso deseando que desaparezca y que se dé más bien una objetividad libre de ser ahí. "Lo decisivo", dice Heidegger, "no es precisamente salir del círculo sino entrar en él del modo justo". ${ }^{45}$ Lo cual significa que es y seguirá siendo tarea prioritaria de una interpretación

43 Martin Heidegger, Ser y tiempo, op. cit., $§ \S 45$ y 63.

44 Martin Heidegger, Phänomenologische Interpretationen zu Aristoteles. op. cit., pp. 237238.

45 Martin Heidegger, Ser y tiempo, op. cit., p. 171. 
confiable la de desarrollar e interpretar sus propias anticipaciones. Lo que se busca no es una reflexión que logre neutralizar o abolir tales anticipaciones sino el hacer reflexivamente consciente la pre-estructura propia para así entablar un diálogo genuino con lo que es y con los otros. Si no lo hacemos el comprender corre peligro de que "ocurrencias y conceptos populares le impongan su tener, ver y concebir previos". 46

Digamos, a manera de recapitulación, que la hermenéutica de Heidegger se presenta como radicalización de la tendencia interpretativa inherente al comprender. Heidegger toma el término "hermenéutica" "en la significación original de la palabra, en la que designa el quehacer de la interpretación", ${ }^{77}$ para enfrentarse al enfoque dominante desde mediados del siglo xix, que ve la razón de ser de la hermenéutica en la elaboración de una doctrina sistemática del comprender con miras a la fundamentación de las ciencias del espíritu. La hermenéutica filosófica apunta así tanto a una auto-interpretación de la facticidad como a una interpretación de la interpretación, buscando que el "ser ahí" pueda llegar a ser transparente para sí mismo. Surgida del curar de sí mismo del "ser ahî", la indagación filosófica, concebida en Ser y tiempo todavía como la realización explícita de la tendencia interpretativa de la movilidad fundamental de la vida, refiere la función auto-esclarecedora de la interpretación al ser del "ser ahi" mismo. Esta intención se manifiesta en la lección de 1923 sobre la "Hermenéutica de la facticidad", donde se afirma que "la hermenéutica tiene la tarea de hacer accesible en su carácter ontológico el ser ahí en cada caso propio a este ser ahí y de tratar de aclarar la auto-enajenación en que se encuentra. En la hermenéutica se forma para el ser ahí la posibilidad de llegar a ser comprensivo para sí mismo". ${ }^{48}$

El ser ahí tiende a pasar de largo ante sí mismo y a no asumir sus más propias posibilidades de transparencia como algo que él mismo conforma. Esto se echa de ver ante todo en el hecho de que el hombre es absorbido por su mundo perdiéndose con ello a sí mismo; así en vez de comprender la propia interpretación de sí mismo, adopta la interpretación acostumbrada que lo libera de la carga del auto-esclarecimiento. El ser ahí "cae en su tradición". ${ }^{49}$ Tal la razón para que la Hermenéutica sólo pueda realizar su tarea "por el camino de la destrucción". ${ }^{50}$ Destrucción significa aquí desmontaje de la tradición en la medida en la que ella encubre al ser ahí para sí mismo y le dispensa de la auto-apropiación. En sentido afirmativo la destrucción

46 Ibid.

47 Ibid., p. 48.

48 Martin Heidegger, Ontologie (Hermeneutik der Faktizität), op. cit., p. 15.

49 Martin Heidegger, Ser y tiempo, op. cit., p. 31.

50 Martin Heidegger, Phänomenologische Interpretationen zu Aristoteles, op. cit., p. 249. 
busca reabrir experiencias originarias de ser ahí, relegadas hace mucho bajo el andamiaje de las categorías ontológicas convencionales. Para volver nuevamente accesibles tales experiencias fundamentales la hermenéutica filosófica no puede eludir la tarea de elaborar una conceptualidad propia. El joven Heidegger fue muy cuidadoso en este punto: para soslayar el peligro de incurrir en una nueva escolastización, él introduce sus conceptos a manera de "indicaciones puramente formales", para destacar que los enunciados sobre el ser de la existencia humana exigen un ejercicio de apropiación por parte del que comprende. Estos enunciados no deben ser comprendidos como proposiciones que describan teóricamente un estado fáctico dado sino como llamados a la apropiación del ser propio a partir del ser ahí respectivo.

\section{El tardío Heidegger y la hermenéutica}

Nos hemos ocupado hasta aquí de la hermenéutica temprana de Heidegger que está en la base de la filosofía hermenéutica desarrollada en la segunda mitad del siglo xx. Al término de este trabajo el lector se preguntará si los atisbos de esa hermenéutica temprana encontraron su desarrollo en el pensamiento tardío de Heidegger a partir de Ser y tiempo. Parecería que la concepción hermenéutica del lenguaje sufre una profunda transformación en la obra tardía, ya que la referencia al lenguaje como "morada del ser" haría evidente que la patencia del ser pase a ocupar el sitio central que tuvo inicialmente la facticidad del ser ahí.

En las recientemente publicadas Contribuciones a la filosofía, escritas de 1936 a 1938, el documento quizá más completo del nuevo acento en el pensamiento de Heidegger, se lee en una de las primeras páginas: "En la filosofía jamás se pueden demostrar las proposiciones [...] porque aquí en principio 'proposiciones' no son lo verdadero ni tampoco aquello sobre lo cual ellas enuncian." 51 Esta advertencia se mantiene vigente hasta 1962, cuando al final de la conferencia "Tiempo y ser", para algunos último hito en el camino del pensamiento heideggeriano, se insiste en que: "Se trata de superar sin descanso los obstáculos que fácilmente tornan insuficiente un decir semejante. El decir del acontecer en forma de conferencia sigue siendo uno de tales obstáculos. Ella ha hablado tan sólo en enunciados proposicionales." 52 Bien podemos imaginar las arduas dificultades con las que tropieza ese decir en tanto no se dé en medio de la lucha con el lenguaje el esfuerzo por mantener el carácter hermenéutico de éste. Una filosofía que se ha percatado del rehusarse como forma fundamental del ser no puede

51 Martin Heidegger, Beiträge zur Philosophie, Gesamtausgabe t. 65, Francfort del Meno, 1989 , p. 13.

52 Martin Heidegger, Zeit und Sein, en Zur Sache des Denkens, Tubinga, 1969, p. 25. 
seguir creyendo ingenuamente que el experimentar la finitud se pueda decir en enunciados proposicionales auto-suficientes. Así se explica la tenaz rebeldía de Heidegger contra la funcionalización del lenguaje como medio informático, impuesta por la técnica planetaria.

Si la comprensión hermenéutica del lenguaje no desaparece con el "giro" otro tanto puede decirse de la tarea crítica de esclarecimiento de la situación hermenéutica propia a través de la interpretación. ${ }^{53}$ La ocupación intensa con la historia del ser, vista por algunos como distanciamiento final de todo esclarecimiento, no es otra cosa que proseguir la destrucción de la tradición - planteada ya en Ser y tiempo- en el sentido de la apropiación reflexiva de nuestra situación histórica de comprensión. El ser ya interpretado que sirve de fundamento a la pre-estructura de nuestro comprender tiene ahora, valiéndose de la historia del ser, que hacerse transparente, es decir, llegar a ser interpretación cabal. El tardío Heidegger está tan consciente del carácter situado o yecto del comprender humano que se concentra casi exclusivamente en la interpretación y en la confrontación del legado ontológico que nos determina. La travesía de la historia avanza sin duda en búsqueda de la transparencia que todo ser ahí debería ganar, transparencia que no es distinta del socrático conocerse a sí mismo, del atisbo en los límites propios, en nuestro inabolible ser yecto, como conciencia de nuestra finitud ante la historia del ser que ahora es.

La filosofía del "giro" surge en último análisis de pensar hasta el fin el carácter de yecto del ser ahí en torno al cual gira la hermenéutica de la facticidad. El ser ahí ya no vale, lo que parecía ser el caso en 1927, como autor potencial de sus proyectos de comprensión, los que ahora recibe de una historia del ser, muy difícilmente perceptible, cuyo esclarecimiento se convierte en la tarea primordial de la hermenéutica. El pensamiento de Heidegger sigue siendo hermenéutico. El que se deje de lado el término "hermenéutica", al igual que casi todos los términos claves de Ser y tiempo, tiene que ver con el destronamiento de la subjetividad que resultó de la radicalización del ser yecto y de la finitud del ser del hombre. Heidegger sucumbió quizá a un cierto malentendido de sí mismo al creer que la filosofía hermenéutica formara parte de la modernidad subjetiva y transcendental, debido probablemente a que en Ser y tiempo concibió su hermenéutica como contrapunto de la modernidad, en nombre del cual hizo el llamado a la destrucción de la tradición ontológica.

Las poquísimas referencias a la Hermenéutica en la obra tardía se encuentran casi todas en el volumen De camino al habla, aparecido en 1959, justamente en el Diálogo acerca del habla entre un japonés y uno que indaga. Interrogado en cuanto al sentido del nombre de "hermenéutica" Hei- 
degger cita sin comentarios la definición de Schleiermacher, "el arte de bien comprender el discurso de otro, principalmente el discurso escrito", ${ }^{4}$, remitiéndose así a algo de lo que se había distanciado explícitamente en la lección de 1923 y tácitamente en Ser y tiempo. A la pregunta de cómo entiende la denominación "hermenéutica" en ésta su obra principal, Heidegger responde sibilina y hasta tautológicamente que significa "más bien la tentativa de determinar, ante todo, lo que es la interpretación a partir de lo hermenéutico". ${ }^{5}$ ¿Y qué quiere decir "lo hermenéutico"? No se debe esperar demasiado, replica Heidegger, "porque la cuestión es enigmática y tal vez ni siquiera se trate de una cosa". ${ }^{56}$ De nuevo la sospecha de lo objetivo y de su disponibilidad, sospecha que apunta hacia lo enigmático e inefable para cuya comprensión se requiere justamente de la hermenéutica.

Hacia la mitad del diálogo, sin embargo, Heidegger da respuesta a la pregunta de qué sea propiamente lo hermenéutico, explicando que se ha de entender a partir del verbo griego èrmeneúein, "aquel hacer presente que lleva al conocimiento en la medida en que es capaz de prestar oído a un mensaje". ${ }^{57}$ En la obra tardía, como vemos, hermenéutica significa traer un mensaje que reclama un oír. Podría decirse que en ningún otro momento de su filosofía haya estado Heidegger más cerca de la tradición hermenéutica. Traer un mensaje sólo es posible por medio del habla; más aún, éste es el quehacer elemental de ella. "El habla es la que da voz (sostiene) a la relación hermenéutica." ${ }^{58} \mathrm{Al}$ final, como vemos, la cuestión de la hermenéutica se funde con la cuestión del habla, pues ¿qué otra cosa es el habla que el participar un mensaje al que un escuchar comprensivo ha de acoger?

"Entonces", concluye el japonés, "cuando yo le pregunto acerca de lo hermenéutico y cuando usted me pregunta acerca de la palabra para lo que entre ustedes se llama habla, nos preguntamos lo Mismo."59 "Esto es manifiesto" 60 -replica Heidegger. El camino de su pensar que se sabía camino del habla es también transitable como camino de la hermenéutica.

Bogotá, junio de 1998

Recibido: 16 de junio de 1999

54 Martin Heidegger, De camino al habla, Odos (Ediciones del Serbal), Barcelona, 1987, p. 89.

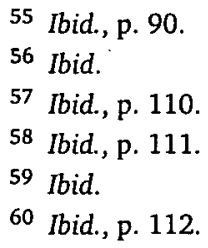

